\title{
CISCA Regimen
}

National Cancer Institute

\section{Source}

National Cancer Institute. CISCA Regimen. NCI Thesaurus. Code C64190.

A regimen consisting of cisplatin, cyclophosphamide and doxorubicin used for the treatment of advanced bladder cancer. 